\title{
The Technique of Shouldice in the Treatment of the Inguinal Hernias at the Hospital Sominé Dolo of Mopti (Mali) Subject of 675 Cases
}

\author{
Abdoulaye Kanté1,2*, Mamadou Alymami Keita ${ }^{3}$, Idrissa Tounkara4, Bréhima Bengaly3, \\ Bréhima Coulibaly3 ${ }^{3}$, Siaka Diallo ${ }^{3}$, Drissa Ouattara1, Babou Ba², Drissa Traoré1, \\ Souleymane Sanogo ${ }^{3}$, Djibril Traoré1, MoustaphaIssa Magané5, Mariam Daou6, \\ Bakary Keita ${ }^{4}$, Birama Togola ${ }^{3}$, Nouhoum Ongoïba ${ }^{3}$ \\ ${ }^{1}$ Service of General Surgery, Sominé Dolo of Mopti Hospital, Mopti, Mali \\ ${ }^{2}$ Laboratory of Anatomy of the Faculty of Medicine and Odontostomatology, Bamako, Mali \\ ${ }^{3}$ Service of Surgery B, CHU Point G, Bamako, Mali \\ ${ }^{4}$ Service of General Surgery, Gabriel Touré, Bamako, Mali \\ ${ }^{5}$ Service of Anesthesia and Resuscitation, CHU Gabriel Touré, Bamako, Mali \\ ${ }^{6}$ Service of Neurology, CHU Gabriel Touré, Bamako, Mali \\ Email: *kanteim@yahoo.f
}

How to cite this paper: Kanté, A., Keita, M.A., Tounkara, I., Bengaly, B., Coulibaly, B., Diallo, S., Ouattara, D., Ba, B., Traoré, D., Sanogo, S., Traoré, D., Magané, M., Daou, M., Keita, B., Togola, B. and Ongoïba, N. (2018) The Technique of Shouldice in the Treatment of the Inguinal Hernias at the Hospital Sominé Dolo of Mopti (Mali) Subject of 675 Cases. Surgical Science, 9, 461-468.

https://doi.org/10.4236/ss.2018.912052

Received: September 15, 2018

Accepted: November 1, 2018

Published: December 17, 2018

Copyright (c) 2018 by authors and Scientific Research Publishing Inc. This work is licensed under the Creative Commons Attribution International License (CC BY 4.0).

http://creativecommons.org/licenses/by/4.0/ (c) (i) Open Access

\begin{abstract}
The objective was to study epidemiological and therapeutic aspects of the inguinal hernia according to the technique of Shouldice. Methodology: we realized a retrospective study, concerning the patients operated for inguinal hernia according to the technique of Shouldice in the service of general surgery of the hospital Sominé Dolo of Mopti, Mali. All the patients operated during the period of study for inguinal hernia according to the technique of Shouldice were included. The patients operated for hernia by other technique than that of Shouldice were not included. Results: The study has been realized in the service of general surgery of the hospital Sominé Dolo of Mopti (Mali). It was about a retrospective study which concerned 25 years from January, 1987 till December, 2012. 675 patients operated according to the technique of Shouldice were registered. The average age was of 49 years $+/-17.7$. There were $90.7 \%$ (612) men. The sex-ratio is 9.7. The farmers, the housewives and the workers represented $51.1 \%$ (115). In $75.2 \%$ (508) the patients consulted for inguinal tumefaction. In operating meadow, the hernia was complicated to $246(36.4 \%)$ patients among whom 72 cases were of recurrence. The hernia constriction was the main complication operating meadow 58.5\% (48/82). The operating suites in one year were simple at $94.2 \%$ (636) of the patients; they were marked by 24 cases of recurrence, 12 cases of neuralgia, 6 cases of
\end{abstract}


testicular atrophy, and 3 cases of keloid. Conclusion: The technique of Shouldice is the technique of choice for the cure of the inguinal hernia in developing countries because of the good result and its little expensive cost with compared with the other techniques using medical devices.

\section{Keywords}

Inguinal Hernia, Technique of Shouldice, Recurrences

\section{Introduction}

The inguinal hernia defines itself as a hernia which makes stemming by the inguinal canal over the cruralarch [1]. About $95 \%$ of the hernias of the groin are inguinal hernias which affect especially the male subject between 20 and 60 years [2]. They represent $10 \%$ of the interventions in digestive surgery. It is one of the most frequent pathologies in general surgery particularly in Africa where it affects approximately $4.6 \%$ of the population [3]. The treatment of the inguinal hernia is essentially surgical. If the diagnosis of the inguinal hernia is simple, the modalities of their treatment remain controversial. The treatment of the inguinal hernia raises the question of the choice among several surgical techniques today offering comparable clinical results but different functional and economic results [2]. In 1996, Simmons concluded that "the intervention of Shouldice is the best conventional technique of cure of the inguinal hernia" [4]. Among the techniques of suture or Herniorrhaphy, the technique of Shouldice is considered the reference process because of the rate of second recurrence of the hernias lower than $1 \%$ published by the School of Toronto [5]. In our country even in developing countries, the majority of the cures of the inguinal hernia are made by the conventional techniques. The objectives of this study were: to study the epidemioclinical and therapeutic aspect of the inguinal hernia according to the technique of Shouldice.

\section{Materials and Methods}

The study has been realized in the service of general surgery of the hospital Sominé Dolo of Mopti (Mali). It was about a retrospective study which concerned 25 years from January, 1987 till December, 2012. The patients operated for an inguinal hernia according to the technique of Shouldice in the service of general surgery at the hospital Sominé Dolo of Mopti were included. The patients operated according to the technique of Shouldice except the service of general surgery of the hospital Sominé Dolo de Mopti or operated according to other techniques were not included. The sampling was exhaustive during the period of study.

The data collection was made through the index cards of inquiries which were filled from files pre-established for every sick person, from register of consultation and the exercise books of operating report. The patients were looked for by going to their places of residence or by phoning them. This methodology al- 
lowed us to see again the majority of our patients. The dependent variable was the existence of the inguinal hernia operated according to the technique of Shouldice. The independent or explanatory variables were the sociodemographic, clinical, therapeutic information and of the post-operative follow-up. The seizure was made on the software Excel, and the analysis made by the software Ear information 7. The used statistical tests were $\mathrm{Khi}^{2}$ and exact Fischer. The value of $\mathrm{p}$ lower than 0.05 was considered significant.

\section{Results}

We collected 675 patients whose average age was of 49 years \pm 17 years with the extremes of 18 and of 76 years. The majority of our patients were male that is 90.7\% (612) and female 9.3\% (63) (Figure 1). The sex-ratio was 9.7. The patients made physical activities intense (farmer, housewife, worker) in $51.1 \%$ (345) of the cases and 21. 3\% (144) had an intellectual activity (state employee, student/pupil).

The motives for consultation or for reference of our patients were essentially the inguinal tumefaction in $75.2 \%$ (508) of the cases, followed by the painful inguinal tumefaction in $5.8 \%$ of the cases (39) (Figure 2). We found factors favorisants (intense effort, multiparity, dysuria, constipation and obesity) to $61 \%$ (412) of the patients. In 58, 2\% (393) of the cases the inguinal hernia was to the right; $35,1 \%$ (237) had a left inguinal hernia and 6, 7\% (45) had a bilateral inguinal hernia.

In operating meadow, the hernia was complicated at $39.6 \%$ (267 cases) of our patients. The types of complication operating meadow were the hernia constriction to $53.9 \%$ (364 cases) of our patients, followed by the second recurrence of the hernia $34.9 \%$ (236) and the hernia craze $11.2 \%$ (76 cases). The patients were operated under local anesthesia in $48.9 \%$ (330 cases), under loco regional anesthesia in $40.4 \%$ (273 cases) and under general anesthesia in $10.7 \%$ (72) of the cases (Figure 3).

We found that $85.8 \%$ ( 579 cases) of the patients were operated by a qualified surgeon and $14.2 \%$ (96 cases) by a learner surgeon. Per operating, the hernia sac contained of hail in $14.2 \%$ (96 cases), of the omentum in 6\% (41 cases), the colon in $5 \%$ ( 34 cases), of hail more the colon in $3.6 \%$ ( 24 cases) and of hail more the omentum in $2.2 \%$ (15) of the cases.

Per operating, we found two incidents, a lesion of the colon and a lesion of hail. The not absorbable thread was used at $96 \%$ (648 cases) of the patients and

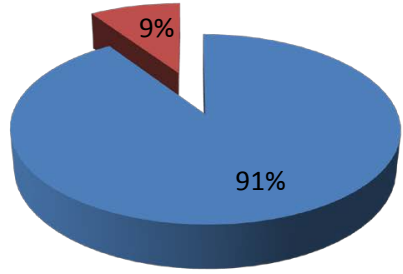

M

- F

Figure 1. Sex. 


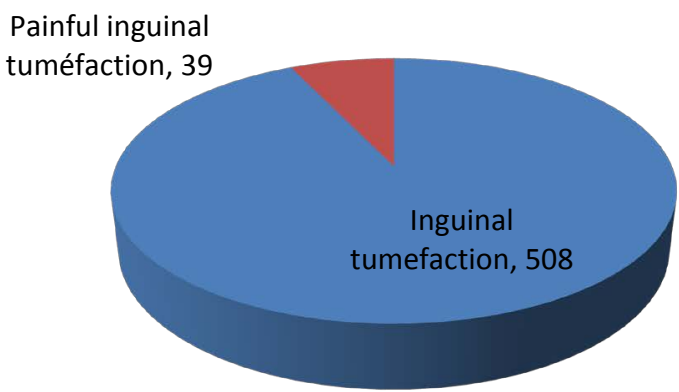

Figure 2. Motives of consultation.

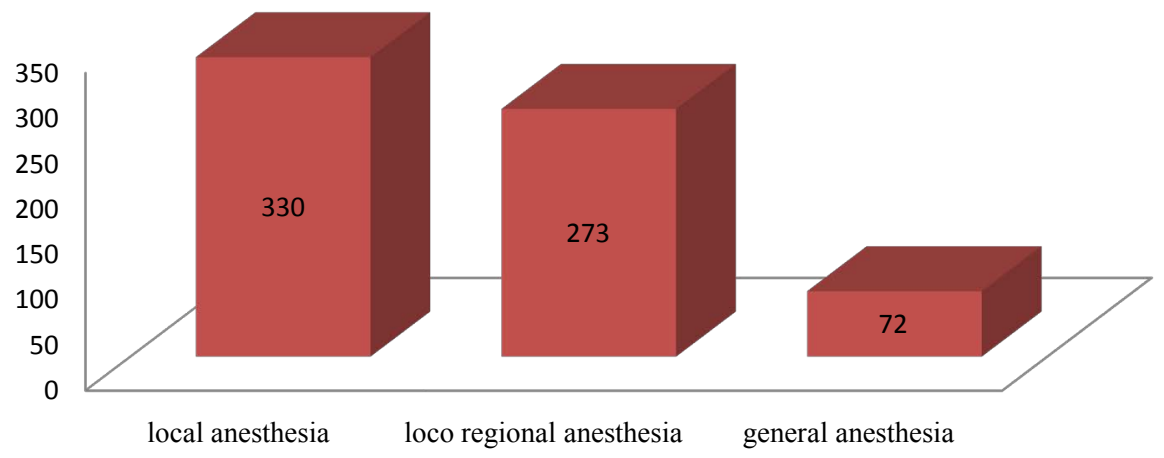

Figure 3. Type of anesthesia.

the absorbable thread to $4 \%$ (27 cases) of the patients. The stay average operating comment was of 4.9 days with extremes of 1 and of 27 days and standard deviation of 3.6. The immediate operating suites ( 0 in 8 days) were marked by an inguinal or scrotal bruise to $7 \%$ (47 cases), an acute pain to $7.2 \%$ and an inflammation in $3.3 \%$ ( 22 cases) of the cases.

In a post-operative month, we had a rate of $5.8 \%$ morbidity (39), makes of $46.2 \%(18 / 39)$ of abscess of the wall, $23.1 \%$ (9/39) of delay of healing, $15.3 \%$ (6/39) of neuralgia, 7.7 (3/39) of acute intestinal obstruction and 7.7\% (3/39) of testicular pain (Figure 4 ).

The nature of the complication in 6 months was the neuralgia in $40.5 \%$ (6 cases), the keloid in $20.3 \%$ ( 3 cases), the testicular atrophy in $13.5 \%$ ( 2 cases), the testicular pain in $6.8 \%$ ( 1 case) and the granuloma on thread in $6.8 \% 1 \mathrm{cas})$. We had seen again $100 \%$ of our one-month-old patients, $64 \%$ a year, $45.8 \%$ in two years and only $2.3 \%$ in 14 years of backward movement. In one year we had $3.5 \%$ (8 cases) of second recurrence of the hernia. In two years the second offense was noticed at $2.6 \%$ (6 cases) of our patients. In 5 years, operating comment the second recurrence of the hernia was noticed at $1.7 \%$ (4 cases) of our seen again patients.

The herniasecond recurrence of the hernia operating comment was not statistically connected to the physical effort at our operated patients $(p=0.9)$. Concerning the sex and the post-operative second offense, there was no statistically significant difference between 2 sexes $(\mathrm{p}=0.8)$. We did not find statistically significant relation between the post-operative second recurrence of the hernia and 


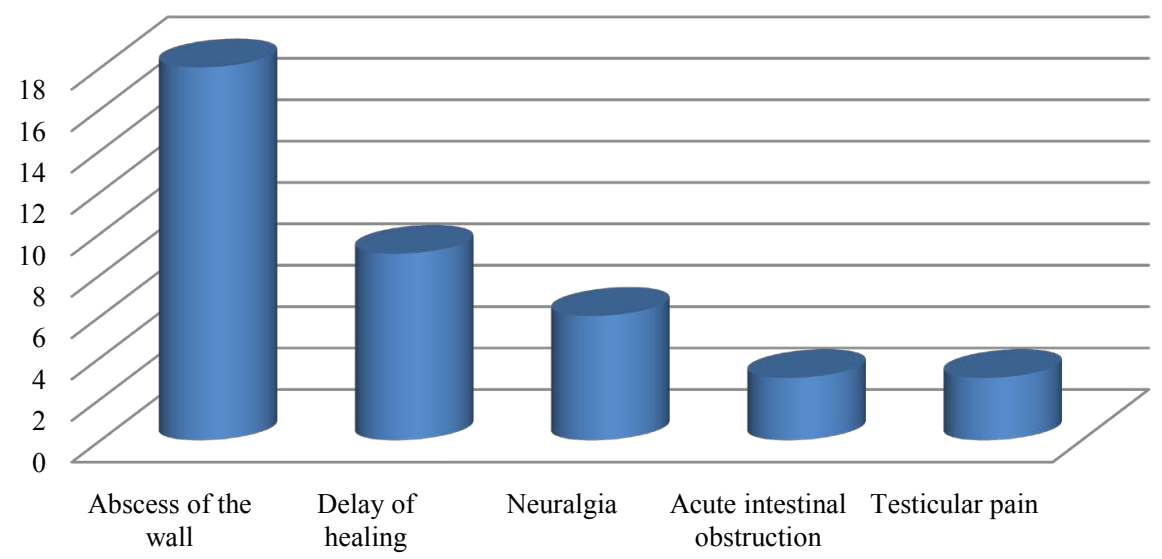

Figure 4. Morbidityin a post-operative month.

the qualification of the first operator $(\mathrm{p}=0.9)$. The constriction of the hernia was not bound to the post-operative second recurrence of the hernia $(p=0.5)$. There was no statistically significant difference between the second recurrence of the hernia operating meadow and the post-operative second offense with one $\mathrm{p}$ $=0.2$. No death bound to the treatment of the inguinal hernia according to the technique of Shouldice was registered.

\section{Discussion}

We found a high frequency of the inguinal hernia at the relatively young people with an average age of 49 years. Most part of these people was male that is $90.7 \%$ with a sex-ratio of 9.7. Certain authors explained this male ascendancy, by an anatomical difference between both sexes [6]. In man the inguinal canal is crossed by the cordon which makes it fragile. What is not the case at the woman whose inguinal canal contains only the round ligament. In developing countries this male ascendancy could also give some explanation by the difficulties which have the women to reach health care. This result could be explained by the fact that in Africa in particular in Mali, the majority of the populations live exclusively agricultural works which request the muscles of the abdominal wall a lot. What is confirmed by the study of Boukinda and al [7] to the Hospital center from Talangai to Brazzaville who found an average age of 40.7 years with a male ascendancy of $84.2 \%$ of the cases.

In this study, $51.1 \%$ of the patients made physical activities intense. The various led studies went up that the labourers are mainly represented, what is an argument to support the theory which asserts that the acquired hernia is bound to the repeated physical effort which, causing every time an intra-abdominal high blood pressure, hunts the mobile viscera towards zones hernia dehiscent where they express themselves gradually [8]. The main complication of the inguinal hernia is the constriction, we found $21.3 \%$. This rate is statistically identical to that brought back by Mehinto and al [9] who found 26.4\% ( $\mathrm{p}=0.76)$ of hernia repressed on 432 cas. The risk of constriction of a hernia during its evolution is from $3 \%$ to $7 \%$ [10]. In $58.2 \%$ of the cases the hernia was to the right; what is 
similar to those obtained by Mehinto and al [9] and Mbah and al [11] who found respectively that $61.69 \%(\mathrm{p}=0.42)$ and $58.1 \%(\mathrm{p}=0.98)$ of their patients had their hernia to the right. The differences are not statistically significant. One of the advantages of the technique of Shouldice is its feasibility under local or loco regional anesthetia which decreases the post-operative morbidity. The majority of our patients were operated under local anesthetia in $48.9 \%$ and under loco regional anesthesia to $40.4 \%$ and for the general anesthesia to $10.7 \%$. El Alaoui and al [12] found that the loco regional anesthesia was widely used at $96.2 \%$ ( $\mathrm{p}=$ $\left.10^{-6}\right)$ patients, followed by the local anesthetia to $2.3 \%\left(\mathrm{p}=10^{-6}\right)$ and of the general anesthesia to $1.5 \%(\mathrm{p}=0.001)$. But the differences are statistically significant. These differences could be due to the size of our sample which is more important and the types of sick person. Campanelli and al [13] found a local anesthetia to $66.76 \%$ of their patients $\left(\mathrm{p}=51 \cdot 10^{-4}\right)$. This difference can be bound to the high number of preoperative complications second recurrence of the hernia and constriction in our study, which sometimes requires a loco regional anesthesia even general. The not absorbable thread was used at $93 \%$ (628) of the patients and the absorbable thread to 7\% (47) for the cure of the hernia. We did not find link between the use of the non-absorbable sons and the arisen of the post-operative second offenses. The immediate operating consequences ( 0 in 8 days) were simple at $86.7 \%$ of the patients, followed by the existence of an inguinal or scrotal bruise to $8 \%$ and by the acute pain to $5.3 \%$.

Our results are lower than those obtained by El Alaoui and al [12] who found that the immediate operating suites were simple at $92.4 \%$ of the patients, followed by a parietal bruise to $3 \%$ and by a scrotal edema to $1.5 \%$. Somewhere else, Backgammon and al [14] found it post-operative immediate, that $33.6 \%$ of the patients had a post-operative painful symptomatology. In the immediate operating suites Sani and al [15] found that $28 \%$ of the patients had small bruises et $14 \%$ of residual pains at the national hospital of Niamey. In our study, we had seen again $100 \%$ of our one-month-old patients, $64 \%$ a year, $45.8 \%$ in two years and $2.3 \%$ in 5 years of backward movement. Our results are similar to those of Millat and al [16] who saw again $75 \%$ of his one-month-old patients, $56 \%$ a year and $67 \%$ in two years. On the other hand Barrier and al [17] had lost of seen only $15 \%$ of his patients for a backward movement of 14 years. In our series, 3.5\% of our patients had done it again in one year of follow-up. Our rate is comparable to that of Wassern and al [18] in Pakistan who found 1.28\%, Harouna in Niger [19] 2\% and Drew and al [20] in England 0.99\%. The stay average operating comment was of 5.9 days with a standard deviation of 3.6 days. Certain authors [12] [19] [21] brought back a duration of post-operative hospitalization which varies between 3 and 5 days.

\section{Conclusion}

The technique of Shouldice is the technique of choice for the cure of the inguinal hernia in developing countries because of the good result. It has for advantage to be able to be realized in all the circumstances, by using a simple and little expen- 
sive material, while assuring a parietal quality repair. It is thus essential for every surgeon practicing in regions under provided with medical care to know this technique, which made the proof of its efficiency and its reproducibility. Besides, the long-term impact of medical prosthesis used in the cure of the inguinal hernia is not still totally clarified.

\section{Conflicts of Interest}

We, authors of this article declare that there is no conflict of interests.

\section{References}

[1] Faure, J.P., Carretier, M. and Richer, J.P. (2003) How Forms an Abdominal Hernia? The Review of the Practitioner, 53, 1639-1644.

[2] Ananian, P., Barrau, K., Balandraud, P. and Treut, Y.P. (2006) Surgical Cure of the Inguinal Hernias of the Adult: Clinical, Functional and Economic Stakes in the Surgical Practices. Journal of Surgery, 143, 76-83.

[3] Kingsnorth, A. and LeBlanc, K. (2003) Hernias Inguinal Incisional. Lancet, 362, 1561-1571. https://doi.org/10.1016/S0140-6736(03)14746-0

[4] Simons, M.P., Kleijnen, J., van Geldere, D., Hoitsma, H.F. and Obertop, H. (1996) Role of the Shouldice Technique in Inguinal Hernia Repair: A Systematic Review of Controlled Trials and a Meta-Analysis. British Journal of Surgery, 83, 734-738. https://doi.org/10.1002/bjs.1800830606

[5] Shouldice, E.B. (2003) The Shouldice Repair for Groin Hernias. Surgical Clinics of North America, 83, 1163-1187. https://doi.org/10.1016/S0039-6109(03)00121-X

[6] Bronstein, J.A., Brévart, C. and Moncade, F. (2012) Hernias of the Groin of the Adult. EMC Gastroenterology, 7, 1-10.

[7] Bounkida, F., Fagniez, P.L. and Julien, Mr. (1993) Epidemiological Profile of Hernias to the Hospital Center from Talangai to Brazzaville; Study Concerning 260 Sick Operated in 12 Months. Medicine of Black Africa, 40, 655-661.

[8] De Goede, B., Timmermans, L., van Kempen, B.J.H., van Rooij, F.J.A., Kazemier, G., Lange, J.F., et al. (2015) Risk Factors for Inguinal Hernia in Middle-Aged and Elderly Men: Results from the Rotterdam Study. Journal of Surgery, 157, 540-546. https://doi.org/10.1016/j.surg.2014.09.029

[9] Mehinto, D.K. et al. (2003) Coverage of Hernias Choked with the Groin at the Adult about 295 Cases (Benin). African Journal of Digestive Surgery, 3, 1-5.

[10] Andresen, K., Bisgaard, T. and Rosenberg, J. (2015) Sliding Inguinal Hernia Is a Risk Factor for Recurrence. Langenbeck's Archives of Surgery, 400, 101-106. https://doi.org/10.1007/s00423-014-1262-y

[11] Mbah, N. (2007) Morbidity and Mortality Associated with Inguinal Hernia in Northwestern. West African Journal of Medicine, 26, 288-292.

[12] El Alaoui, M., Berrada, S., El Mouatacim, K. and Kadiri, B. (1995) The Technique of Shouldice in the Treatment of the Inguinal Hernias about 130 Cases. Maghreb Journal of Medicine, 53, 6-8.

[13] Campanelli, G., Pettinari, D., Nicolosi, F.M., Cavalli, M. and Avesani, E.C. (2006) Inguinal Hernia Recurrence: Classification and Approach. Hernia, 10, 159-161. https://doi.org/10.1007/s10029-005-0053-3

[14] Backgammon, E., Giordan, J., Puche, P., Fabre, J.M., Domergue, J., Navarro, F. and 
Eledjam, J.J. (2004) Evaluation of the Coverage of the Inguinal Hernias in Ambulatory Surgery. Annals of Surgery, 129, 138-143.

[15] Sani, R., Gbane, M., Hennaux, M., Of Groof, D., Mansour, A. and Ben Ousmane, I. (2007) Coverage of the Simple Inguinal Hernias: Comparison of the Economic and Therapeutic Aspects of a Hospital of District and the National Hospital of Niamey of Niger. Medicine of Black Africa, 54, 215-219.

[16] Al Millat, B., et al. (2007) The Federation of Search in Surgery; Cure of Inguinal Hernia in Man: Randomize Multicentrique Study Comparing Coelisocopy versus Open Surgery. Journal of Surgery, 144, 119-124.

[17] Barrier, A., et al. (2007) Inguinal Hernias Deadlines of Appearance of Second Recurrence of the Hernias. Journal of Surgery, 144, 125-127.

[18] Awan, W.S., et al. (2010) Lichtenstein Repair Shouldice versus: Professional. British Medical Journal, 17, 355-359.

[19] Harouna, Y., Seibou, A., Manzo, R., Abdou, I. and Bazira, L. (2000) The Simple Inguinal Hernia of the Adult: Study Economic Medico about 244 Cases. Medicine of Black Africa, 47, 292-297.

[20] Drew, P.J., Hartley, J.E. and Qureshi, A. (1998) Primary Inguinal Hernia Repair: How Audit Changed a Surgeon's Practice. Journal of Radiology, 91, 583-584. https://doi.org/10.1177/014107689809101109

[21] Gerbitz, J., Rose, N. and Eberle, C. (2001) Quality Control after Operation of a Hernia. Swiss Surgery, 7, 105-109. https://doi.org/10.1024/1023-9332.7.3.105 